\title{
The Study of Plasma Homocysteine and Lipid Profile Levels as Markers of Cardiovascular Disease in Pre and Postmenopausal Women
}

\author{
Dr. Meera $S^{1}$, Dr. Muruga ${ }^{2 *}$ \\ ${ }^{1}$ Professor and HOD, Department of Biochemistry, Mysore Medical College and Research Institute, Mysuru, Karnataka, India \\ ${ }^{2}$ Assistant Professor, Department of Biochemistry, Father Muller Medical College, Mangalore, India
}

DOI: $\underline{10.36348 / \text { sijb.2020.v03i05.003 }}$

| Received: 09.05.2020 | Accepted: 16.05.2020 | Published: 19.05.2020

*Corresponding author: Dr. Muruga

\section{Abstract}

Postmenopausal women are at risk of cardiovascular disease due to the cessation of estrogen hormone secretion by the ovaries. Based on a few studies in the western population, the plasma homocysteine level has been shown to be a more reliable indicator of cardiovascular risk in elderly women, when compared to conventional markers like lipid profile. However, not many studies have been done in India regarding the role of homocysteine and lipid profile as a risk factor in causing the cardiovascular disease in postmenopausal women. Objectives: 1. To estimate plasma homocysteine and lipid profile levels in pre and post-menopausal women. 2. To compare and correlate homocysteine and lipid profile levels in pre and post-menopausal women. 48 confirmed cases of postmenopausal women and 48 regularly menstruating premenopausal women were included in the study after screening for inclusion and exclusion criteria. Blood samples were collected from the subjects and processed for estimation of lipid profile and plasma homocysteine levels. The BMI was significantly higher in the postmenopausal women as compared to premenopausal women. There was no significant difference in the mean values of lipid parameters between the two groups. The mean plasma homocysteine level (19.93 $\pm 8.09)$ was significantly increased in postmenopausal women when compared to premenopausal women (10.52 \pm 2.62$)$ and it also showed a positive correlation as age advances age. In our study we found that, there is a significant increase in homocysteine levels than lipid profile parameters, hence homocysteine may be consider as a sensitive marker of CVD's in postmenopausal women.

Keywords: Plasma Homocysteine, Lipid Profile, Hyperhomocysteinemia, Dyslipidemia, Cardiovascular Disease, Premenopausal, Postmenopausal, Coronary Artery Disease.

Copyright @ 2020: This is an open-access article distributed under the terms of the Creative Commons Attribution license which permits unrestricted use, distribution, and reproduction in any medium for non-commercial use (NonCommercial, or CC-BY-NC) provided the original author and source are credited.

\section{INTRODUCTION}

Cardiovascular disease (CVD) is a leading cause of death among women. About $53 \%$ of female deaths are due to CVD particularly coronary heart disease, congestive heart failure and stroke. The incidence of cardiovascular disease increases with age as the risk increases markedly after menopause $[1,2]$.

Premenopausal women are relatively protected from the coronary artery disease (CAD) and atherosclerosis as compared to postmenopausal women and this protection is attributed to the effects of female sex hormone estrogen secreted by the ovarian follicles. World Health Organization (WHO) defines the Menopause as "the permanent cessation of menstruation as a result of the loss of ovarian activity [1]". It is usually a natural transition which occurs in women in their late 40s and early 50s signaling the end of the fertile phase of women's life. The average menopausal age in Indian population is 44years [3]. The estradiol level decreases drastically after menopause from $40-350 \mathrm{pg} / \mathrm{ml}$ in premenopausal women to 13 $\mathrm{pg} / \mathrm{ml}$ in post menopausal women [4].

Post menopause is defined as the time after which a woman has experienced twelve consecutive months of amenorrhea without a period. Due to lack of estrogens in the body, post menopausal women are more prone for cardiovascular diseases, osteoporosis, obesity, hypertension and diabetes [5].

The hormonal changes associated with the menopause e.g low level of plasma estrogen and marked increase in follicle stimulating hormone (FSH) levels exert a significant effect on metabolism of plasma lipids and lipoproteins, leading to atherosclerosis thereby increases the risk of CVD in post-menopausal women[6,7]. 
Elevated level of plasma homocysteine (pHcy) is recognized as an independent risk factor for cardiovascular disease and atherosclerosis. Hyperhomocysteinemia (HHcy) is associated with myocardial infarction, coronary artery disease, strokes, genetic disorders, Alzheimer's disease and loss of cognitive functions, neural tube defects, placental infarcts, abruptio placenta, eclamplsia etc[5].

Thus hyperhomocysteinemia and dyslipidemia induce atherosclerosis, thereby increase the risk of developing cardiovascular disease in post menopausal women. Hence the present study has been taken up to assess the levels of homocysteine and lipid profile as risk markers of cardiovascular disease in postmenopausal women with following objectives:

\section{Objectives of the Study}

1. To estimate plasma homocysteine and lipid profile levels [TC, TG, HDL, LDL and VLDL] in pre and post menopausal women.

2. To compare and correlate homocysteine and lipid profile levels in pre and post menopausal women.

\section{MATERIALS AND METHODS}

The study was conducted in the Department of Biochemistry in association with Obstetrics and Gynecology department in our Institution. Ethical Clearance was obtained from the Institutional Ethical Committee. The total number of study subjects was 96 . Based on the following inclusion and exclusion criteria, the cases and controls were selected for the study.

\section{Inclusion Criteria}

- 48 confirmed Postmenopausal women attending the Gynecology OPD were considered as cases for the study.

- 48 regular menstruating premenopausal women were considered as controls for the study

\section{Exclusion Criteria}

- Known case of Diabetes Mellitus, Hypertension, obesity, CVD, hepatic, metabolic and renal disease, any neoplasia, arthritis or any other inflammatory conditions and those on hormonal replacement therapy and lipid lowering drugs were excluded from the study.

\section{Collection of blood samples}

After getting the informed consent from the subjects, $2.5 \mathrm{ml}$ of fasting blood samples were collected for lipid profile in a plain vacutainer tube and $2.5 \mathrm{ml}$ of blood sample were collected in EDTA tubes for homocysteine estimation. In premenopausal group the sample was collected on $7^{\text {th }}$ day of the last menstrual period.

Samples were centrifuged at $3000 \mathrm{rpm}$ to separate serum and plasma for the analysis of lipid profile and homocysteine estimation.

The following methods were used for the analysis of lipid profile parameters and homocysteine estimation.

1. Total cholesterol by enzymatic CHOD-PAP method.

2. Triglycerides by enzymatic GPO-PAP method.

3. HDL cholesterol by direct method.

4. LDL cholesterol by Friedwald's formula

5. VLDL cholesterol by using formula = Triglycerides $/ 5$

6. Total plasma homocysteine levels by enzymatic method

\section{Statistical Method}

Descriptive statistical analysis has been carried out in the present study. Results on continuous measurements are presented as mean standard deviation (SD) and results on categorical measurements are presented as number $(\%)$. Significance is assessed at $5 \%$ level of significance. Student't-test has been used to find the significance of study parameters on continuous scale between the two groups.

\section{RESULTS}

Total numbers of subjects were 96, which included 48 confirmed post menopausal women as cases and 48 regularly menstruating premenopausal women as controls.

The demographic data (age, height, weight, BMI and duration of years of menopause) and biochemical parameters (Total homocysteine (tHcy) ,Total cholesterol (TC), Triglycerides (TG), High density lipoproteins (HDL), Low density lipoproteins, and Very low density lipoproteins (VLDL) were included in the study.

Table-1: Demographic profile of pre and postmenopausal women

\begin{tabular}{|l|l|l|}
\hline & Post menopausal women & Premenopausal women \\
\hline Age (yrs) & $58.93 \pm 10.79$ & $33.96 \pm 8.5$ \\
\hline Weight (kg) & $57.06 \pm 10.61$ & $53.38 \pm 6.5$ \\
\hline Height $(\mathbf{c m})$ & $143.6 \pm 10.71$ & $149.1 \pm 9.72$ \\
\hline BMI (kg/m ${ }^{2}$ ) & $27.6 \pm 4.46$ & $24.26 \pm 3.21$ \\
\hline Duration of menopause (yrs) & $12.9 \pm 10.24$ & -------- \\
\hline
\end{tabular}


The distribution of BMI in pre and post menopausal women is shown in Table 1. This clearly demonstrates that post menopausal women are overweight when compared to premenopausal women.

Table-2: Comparison of lipid profile parameters in pre and post menopausal women:

\begin{tabular}{|c|c|c|c|c|}
\hline & $\begin{array}{c}\text { Post menopausal women } \\
\text { (Mean } \pm \text { standard deviation) }\end{array}$ & $\begin{array}{c}\text { Pre menopausal women } \\
\text { (Mean } \pm \text { standard deviation) }\end{array}$ & t value & p value \\
\hline Total Cholesterol & $176.63 \pm 55.36$ & $160.66 \pm 33.71$ & 1.70 & 0.09 \\
\hline HDL & $42.6 \pm 13.26$ & $46.26 \pm 14.55$ & 1.28 & 0.201 \\
\hline LDL & $104.61 \pm 41.85$ & $94.25 \pm 30.6$ & 1.38 & 0.17 \\
\hline VLDL & $27.70 \pm 17$ & $22.44 \pm 11.44$ & 1.78 & 0.078 \\
\hline TG & $138.42 \pm 85.05$ & $112.63 \pm 56.9$ & 1.74 & 0.084 \\
\hline
\end{tabular}

The mean value of Total cholesterol, LDL, VLDL and Triglycerides were increased in post menopausal women when compared to premenopausal women and the mean value of HDL is decreased in postmenopausal women when compared to premenopausal women (table 2).Though the values are showing increased in TC, LDL, VLDL, TG and decrease in HDL in post menopausal women when compared to premenopausal women, the values are not statistically significant.

Table-3: Homocysteine levels in post menopausal and premenopausal women

\begin{tabular}{|l|c|c|c|c|}
\hline & $\begin{array}{c}\text { Post menopausal women } \\
\text { (Mean } \pm \text { standard deviation) }\end{array}$ & $\begin{array}{c}\text { Pre menopausal women } \\
\text { (Mean } \pm \text { standard deviation) }\end{array}$ & t value & p value \\
\hline Homocysteine & $19.93 \pm 8.09$ & $10.52 \pm 2.62$ & 7.66 & $<0.0001$ \\
\hline
\end{tabular}

The mean value of plasma homocysteine level is increased in post menopausal women when compared to premenopausal woman and it shows statistically very significant (Table 3). Mean values of plasma homocysteine in post menopausal women is twice the values of premenopausal women.

Table-4: Distribution of Homocysteine levels according to age groups

\begin{tabular}{|c|c|c|c|}
\hline Age group & $\begin{array}{c}\text { Homocysteine value } \\
\text { (Mean value in micromol/dl) }\end{array}$ & F value & p-value \\
\hline 16 to 24 & 11.01 & & \\
\hline 25 to 34 & 11.6 & \multirow{3}{*}{14.378} & \multirow{2}{*}{$<0.0001$} \\
\hline 35 to 44 & 9.85 & & \\
\hline 45 to 54 & 19.10 & & \\
\hline 55 to 64 & 18.36 & & \\
\hline 65 to 74 & 18.07 & & \\
\hline$\geq 75$ & 28.9 & & \\
\hline
\end{tabular}

Table 4 shows the distribution of plasma homocysteine levels according to age groups. As the age advances in women the values of plasma homocysteine increases accordingly. The $\mathrm{p}$ value is less than 0.0001 which indicates statistically it is very significant.

\section{DISCUSSION}

CVDs are the major cause of illness and death in women. Premenopausal women are relatively protected from coronary artery disease and atherosclerosis as compared to post menopausal women. This protection is attributed to the effects of estrogen hormone. Estrogen has several cardioprotective mechanisms that stabilizes the endothelial cell, changes the vascular tone by increasing the nitrous oxide production and enhances the antioxidant effects. All these cardio-protective mechanisms diminish as the menopausal transition is met and the incidence of cardiovascular disease increases following menopause as acknowledged by various studies [5].
Table-1 shows the demographic data of the study. The mean age in the post menopausal women is $58.93 \pm 10.79$ years and in the premenopausal women is $33.96 \pm 8.5$ years. This finding is in accordance with a study by Shenoy and Vernekar[8].

BMI is an indicator of obesity which is an independent risk factor for cardiovascular disease. The present study showed that, there is increase in BMI in postmenopausal women with mean \pm standard deviation of $27.6 \pm 4.46$ as compared to premenopausal women with mean \pm standard deviation of $24.26 \pm 3.21$. This indicates that, the postmenopausal women are overweight when compared to premenopausal women.

In our study, there is an increase in the mean values of total cholesterol (TC), triglycerides (TG), low density lipoprotein (LDL) and decrease in HDL level in post menopausal women when compared to premenopausal women (Table-2). These values were not statistically significant. These statistical 
insignificant values may be due to a reduced amount of sample size. These findings of our study are in accordance with other studies done by Kalavathi et al. Gulab Kanwar et al. Usoro et al. Igweh et al. [9]. In our study there is decrease in the HDL cholesterol level in postmenopausal women which is consistent with studies done by Nwagha et al.[10], Srinivas et al. [11]. The cardio-protective action of HDL cholesterol is lost due to reduction in estrogen level.

Table 3 reveals increase in homocysteine levels in postmenopausal women when compared to premenopausal women, which is statistically very significant with $\mathrm{p}$ value of $<0.0001$. Our findings were in accordance with Fernandez Miranda et al. [12] and Ozkan Y et al. [13]. In our study we also observed, as the age increases the homocysteine levels were also increased. In conclusion, the elevated levels of plasma Hcy and altered lipid profile parameters in the postmenopausal women must therefore be viewed as a characteristic of older age and of its metabolic consequences.

Cardiovascular risk rises as the age advances. More than one in three female adult has some form of CVD. An overall increase in heart attacks among women is seen about 10 years later. But for women the symptoms can become more evident after the onset of menopause. Menopause alone does not cause CVD however certain risk factors increases around the time of menopause i.e; high fat diet, smoking, physical inactivity can also become the risk of cardiovascular disease. Following menopause estrogen level declines which may affect in altering the lipid metabolism and increase in total homocysteine level. In our study we found that, there is a significant increase in homocysteine levels than lipid profile parameters, hence homocysteine may be consider as a newer and sensitive marker of CVD's in postmenopausal women.

\section{REFFERENCE}

1. Anitha, D., Sumangala, P., Manjunatha, A., Shrilaxmi, B., Gouher, B. (2012). Study of Atherosclerotic Risk Factors in Post-menopausal Women, International Journal of Biomedical and Advanced Research, 3(8):645-647.

2. Bhagya, V., Hemaletha, N.R., Veeranna, H.B., Banu, V. (2011). Serum Lipid Profile in Prepubertal, Reproductive and Post-Menopausal
Women, International Journal of Biomedical and Adavanced Research, 2(3): 639-642.

3. Ringa, V. (2000). Menopause and Treatments. Quality of Life Research, 9(6):695-707.

4. Yusouff, Dawood, M. (1993). Menopause, Chapter27 in Textbook of Gynaecology 2nd edition, Larey J Copeland, John F Jarrel, W B Saunders Company, 606.

5. Dimitrova, K. R., DeGroot, K., Myers, A. K., \& Kim, Y. D. (2002). Estrogen and homocysteine. Cardiovascular research, 53(3), 577-588.

6. Swapnali, R. K., Kisan, R., \& Murthy, D. S. (2011). Effect of menopause on lipid profile and apolipoproteins. Al Ameen J Med Sci,4(3), 221228.

7. Kalavathi, L., Dhruvanarayan, H. R., \& Zachariah, E. L. I. Z. A. B. E. T. H. (1991). Plasma estradiol and lipid profile in perimenopausal women. Indian journal of physiology and pharmacology, 35(4), 260-262.

8. Shenoy, R., \& Vernekar, P. (2015). Fasting lipid profile in pre-and postmenopausal women: a prospective study. International Journal of Scientific Study, 3(9), 116-119.

9. Igweh, J. C., Nwagha, I. U., \& Okaro, J. M. (2005). The effects of menopause on the serum lipid profile of normal females of South East Nigeria. Nigerian journal of physiological sciences, 20(1), 48-53.

10. Nwagha, U. I., Ikekpeazu, E. J., Ejezie, F. E., Neboh, E. E., \& Maduka, I. (2010). Atherogenic index of plasma as useful predictor of cardiovascular risk among postmenopausal women in Enugu, Nigeria. African health sciences, 10(3).

11. Kilim, S. R., \& Chandala, S. R. (2013). A comparative study of lipid profile and oestradiol in pre-and post-menopausal women. Journal of clinical and diagnostic research: JCDR, 7(8), 1596.

12. Fernandez-Miranda, C., Manuel, J. B., Muelas, M., Gómez, P., \& Díaz-Rubio, P. (2001). Influence of menopausal status in homocysteine plasma levels. Medicina clinica, 116(6), 206-208.

13. Özkan, Y., Özkan, E., \& Şimşek, B. (2002). Plasma total homocysteine and cysteine levels as cardiovascular risk factors in coronary heart disease. International journal of cardiology, 82(3), 269-277. 